\title{
Decreased incidence of glaucoma in children with asthma using inhaled corticosteroid: a cohort study
}

\author{
Ling-Sai Chang ${ }^{1,2,3, *}$, Hui-Ching Lee ${ }^{4, *}$, Yuh-Chyn Tsai ${ }^{4, *}$, Lien-Shi Shen ${ }^{4}$, Ching-Ling \\ $\mathrm{Li}^{4}$, Shih-Feng Liu ${ }^{4,5}$ and Ho-Chang Kuo ${ }^{1,3}$ \\ ${ }^{1}$ Kawasaki Disease Center, Kaohsiung Chang Gung Memorial Hospital, Taiwan, China \\ ${ }^{2}$ Graduate Institute of Clinical Medical Sciences, College of Medicine, Chang Gung University, Taiwan, China \\ ${ }^{3}$ Department of Pediatrics, Kaohsiung Chang Gung Memorial Hospital and Chang Gung University College of Medicine, \\ Taiwan, China \\ ${ }^{4}$ Department of Respiratory Therapy, Kaohsiung Chang Gung Memorial Hospital, Taiwan, China \\ ${ }^{5}$ Division of Pulmonary and Critical Care Medicine, Department of Internal Medicine, Kaohsiung Chang Gung Memorial \\ Hospital and Chang Gung University College of Medicine, Taiwan, China \\ *These author have contributed equally to this work \\ Correspondence to: Shih-Feng Liv, email: liuphysico@yahoo.com.tw \\ Ho-Chang Kuo, email: dr.hckuo@gmail.com, erickuo48@yahoo.com.tw \\ Keywords: asthma; child; glaucoma; inhaled corticosteroid; taiwan national health \\ Received: June 13,2017 Accepted: October 04, $2017 \quad$ Published: November 01, 2017 \\ Copyright: Chang et al. This is an open-access article distributed under the terms of the Creative Commons Attribution License \\ 3.0 (CC BY 3.0), which permits unrestricted use, distribution, and reproduction in any medium, provided the original author and \\ source are credited.
}

\section{ABSTRACT}

Among the anti-inflammatory medications used for treating asthma, corticosteroids are the most effective. The effects of orally administered corticosteroids on intraocular pressure and lens opacity have been well defined, but the influence of inhaled corticosteroids (ICS) on children has yet to be clearly explained. Therefore, we used a nationwide cohort database to investigate glaucoma in childhood asthma patients using ICS. We analyzed a dataset of 1,000,000 randomly sampled individuals from Taiwan's 2000 National Health Insurance Research Database. The study cohort included 5,380 patients who were first diagnosed with asthma (ICD9: 493.X) diagnosis when they were six years old or younger. All subjects were followed through December 2011. We applied Cox's proportional hazard model to determine whether ICS use has a correlation with glaucoma. Of the 5,380 patients enrolled in this study, we identified 1,232 patients who had used ICS and 4,148 patients who had no history of ICS administration throughout the follow-up period. The prevalence of glaucoma was significantly lower in patients using ICS, with a $\mathbf{0 . 5 2 - f o l d ~ d e c r e a s e d}$ risk of developing glaucoma in comparison to the control group [adjusted hazard ratio (HR) $0.52,95 \%$ confidence interval (CI) $0.28 \sim 0.96$ ]. Among the evaluated comorbidities, cataract was positively associated with glaucoma in asthma children (adjusted HR 8.22; $95 \% \mathrm{CI}=2.59 \sim 26.12$ ). This study provides not only the first but also strong evidence that the glaucoma incidence in the ICS group is lower than that in the non-ICS group in children with asthma. Further consultation with an ophthalmologist regarding the highrisk group of asthma children with cataracts is necessary.

\section{INTRODUCTION}

Asthma is one of the most widespread chronic childhood diseases, often starting in children under the age of six years [1]. This disease is commonly treated with corticosteroids. Short-burst oral corticosteroids are frequently considered for treating young children admitted to the hospital with symptoms indicating atopic asthma [2]. Meanwhile, inhaled corticosteroids (ICS) can effectively treat multiple-trigger wheeze in preschool-age children [3]. 
Side effects caused by ICS usage are particularly important when taken by children because of the disruption to the hypothalamic-pituitary-adrenal axis function, bone turnover, osteoporosis, and growth suppression [4]. Furthermore, such adverse effects as candidiasis, cataracts, glaucoma, and osteoporosis, which may be caused by inhaled corticosteroids in the elderly, are quite concerning, as well [5]. As for systemic corticosteroids, the increased risk of developing glaucoma has been well documented [6]. Decreased trabecular meshwork outflow is regarded as the primary cause of steroid-induced iatrogenic glaucoma [6]. ICS were created to target their delivery into the lungs, which reduces the systemic side effects commonly caused by oral corticosteroids. In fact, the safety profile of all ICS preparations is considerably better than that of oral corticosteroids. Using ICS therapy to treat asthma does not influence the risk of developing glaucoma in adults [5]. However, in an observational case series that included five children with leukemia under the age of six years, elevated intraocular pressure was seen in all those who received systemic steroids [7]. Kwok et al. found that the steroid intraocular pressure-increasing effect was greater in children under the age of ten years with topical dexamethasone [8]. However, little has been discovered with regard to the likelihood of developing glaucoma in preschool-age children, especially concerning inhaled corticosteroids. The importance of the topic and scarceness of relevant data led us to explore the correlation between glaucoma and ICS in young children.

In Taiwan, the National Health Insurance (NHI) program has been covering nearly all of Taiwan's inhabitants since 1996, and all claims data are gathered by the National Health Insurance Research Database (NHIRD) [9]. Currently, the complete database may be one of the largest such health insurance databases in the world. As a result, researchers can easily conduct a nationwide medical use study using this highly computerized database. In this study, we used data from Taiwan's NHIRD to evaluate the relationship between glaucoma and ICS use.

\section{RESULTS}

\section{Patient characteristics of ICS users and non-ICS users}

This study cohort included the data of 91,363 children under the age of six years old from 1997 to 2001. Of those, 5,386 children were admitted to the hospital or visited outpatient clinics more than three times for asthma during the study period. We excluded children that had been previously diagnosed with glaucoma $(n=6)$, resulting in 5,380 patients, including 1,232 ICS users and 4,148 non-ICS users, being used in our final analysis. Differences in income and comorbidities like prematurity, myopia, cataract, and diabetes were eliminated between the ICS users and non-users (all p-values > 0.05). Table 1 shows the demographic characteristics of ICS users versus non-ICS users. Our sample had significantly fewer ICS-users than non-ICS users (1,232 vs. 4,148), and male patients were found to have a higher rate of ICS usage ( $798 / 3309$ vs. $434 / 2071, p=0.0073$ ) than female patients. The median age of patients was 3.12 years old, and ICS was prescribed more frequently for children above the age of 3.12 years old $(53.9 \%$ vs. $46.1 \%$, $\mathrm{p}=0.0025)$.

\section{A lower incidence of glaucoma seen in the ICS cohort than in the non-ICS cohort}

By the end of the follow-up period, 12 patients in the ICS group and 76 in the control group had developed glaucoma. A reduced risk of glaucoma was observed in children treated with ICS compared to the group not treated with ICS during the follow-up period $(\mathrm{HR}=0.54,95 \% \mathrm{CI}=0.29 \sim 0.98)$ (Table 2). Once we adjusted for certain comorbidities, age, gender, and socioeconomic status, the risk of glaucoma in the asthma group treated with ICS remained low ( $\mathrm{HR}=0.52$, $95 \% \mathrm{CI}=0.28-0.96)$. The Kaplan-Meier survival analysis revealed a significantly lower cumulative probability of glaucoma among ICS users when compared with nonusers during the follow-up period (Log-Rank $\mathrm{p}=0.0408)$ (Figure 1).

\section{Factors that may affect the development of glaucoma in asthma patients}

Patients with cataract were at a greater risk of developing glaucoma (adjusted HR, 8.22; 95\% CI, 2.5926.12). The incidence of glaucoma in patients in the noncataract and cataract groups were 132.51 and 1091.39 per 100,000 person-years, respectively (Table 2 ). On the other hand, multivariate analyses indicated that premature birth was not correlated with an increased glaucoma risk. The glaucoma incidence for myopia and non-myopia patients in the sample were 55 and 33, respectively, for an incidence rate of 150.27 and 118.62 per 100,000 person-years. Only one child with asthma and glaucoma was found among the 47 diabetic patients. We did not observe any correlation between myopia or diabetes and developing glaucoma during the follow-up period (adjusted HR 1.20; $\mathrm{CI}=0.78-1.85$; adjusted HR 1.28; $\mathrm{CI}=0.18-9.17$, respectively).

\section{DISCUSSION}

In this population-based cohort study, we found that preschool children with asthma prescribed ICS had a significantly lower likelihood of developing glaucoma. Nevertheless, further research must be carried out with regard to the mechanisms for the reduced glaucoma risk associated with ICS use. 
Table 1: Characteristics of ICS and non-ICS users in preschool-age children with asthma

\begin{tabular}{|c|c|c|c|c|c|}
\hline \multirow[t]{2}{*}{ Variables } & \multicolumn{2}{|c|}{ All patients } & \multirow{2}{*}{$\begin{array}{c}\begin{array}{c}\text { Patient with ICS } \\
\text { use }\end{array} \\
\text { n (\%) }\end{array}$} & \multirow{2}{*}{$\begin{array}{l}\text { Without ICS use } \\
\mathrm{n}(\%)\end{array}$} & \multirow[t]{2}{*}{ p-value } \\
\hline & n & $(\%)$ & & & \\
\hline \multicolumn{6}{|l|}{ Age group } \\
\hline $0 \sim \leq 3.12 \mathrm{y}$ & 2684 & 49.89 & $568(46.10)$ & $2116(51.01)$ & $0.0025^{*}$ \\
\hline$>3.12 \mathrm{y}$ & 2696 & 50.11 & $664(53.90)$ & $2032(48.99)$ & \\
\hline \multicolumn{6}{|l|}{ Gender } \\
\hline Female & 2071 & 38.49 & $434(20.96)$ & $1637(79.04)$ & $0.0073^{*}$ \\
\hline Male & 3309 & 61.51 & $798(24.12)$ & $2511(75.88)$ & \\
\hline \multicolumn{6}{|l|}{ Income (NTD) } \\
\hline$<15840$ & 5298 & 98.48 & $1217(22.97)$ & $4081(77.03)$ & 0.2171 \\
\hline$\geq 15840 \sim<21900$ & 62 & 1.15 & $9(14.52)$ & $53(85.48)$ & \\
\hline$\geq 21900$ & 20 & 0.37 & $6(30.00)$ & $14(70.00)$ & \\
\hline \multicolumn{6}{|l|}{ Medical disease } \\
\hline $\begin{array}{l}\text { Prematurity (ICD } \\
765)\end{array}$ & 29 & 0.54 & $9(31.03)$ & $20(68.97)$ & 0.2958 \\
\hline Myopia (ICD 367.1) & 3051 & 56.71 & $725(23.76)$ & $2326(76.24)$ & 0.0846 \\
\hline Cataract (ICD 366) & 24 & 0.45 & $5(20.83)$ & $19(79.17)$ & 0.8092 \\
\hline Diabetes (ICD 250) & 47 & 0.87 & $11(23.40)$ & $36(76.60)$ & 0.9341 \\
\hline
\end{tabular}

a) ICD, The International Statistical Classification of Diseases and Related Health Problems, 9th Revision; ICS, inhaled corticosteroids; NTD, New Taiwan Dollars.

b) ${ }^{*} \mathrm{p}<0.05$.

Glaucoma is a complex neurodegenerative disease that causes blindness. Many studies have shown that glaucomatous neuropathy may involve immunological factors $[10,11]$. For example, one previous study found that serum interleukin (IL)-4 and IL-6 cytokines produced by $\mathrm{T}$ helper cell 2 were elevated in glaucoma patients; these cytokines also activate B cells to produce IgE [12]. In a retrospective cross-sectional study of 1,652 participants in the National Health and Nutrition Examination Survey (NHANES), the authors concluded that sensitivity to cat and cockroach antigens were associated with an increased likelihood of developing glaucoma [13]. Rubbing one's eyes is another common sequelae of allergic inflammation and has been indicated as a cause of optic neuropathy that can imitate the mechanism for glaucoma [14]. As with allergic rhinitis, asthma has a high comorbidity with allergic conjunctivitis (AC) [15]. Allergic conjunctivitis occurs frequently in preschool children and even more so in preschool children with asthma and allergic rhinitis [16]. Atopic keratoconjunctivitis and vernal keratoconjunctivitis (VKC) involve both IgE and non-IgE mechanisms. A severe bilateral chronic allergic inflammatory disease of the ocular surface, VKC has been reported to be associated with asthma. Continuous uncontrolled inflammation can result in permanently reduced or a complete loss of vision in children suffering from VKC. Topical corticosteroids are among the most potent pharmacologic agents used to treat the more severe variants of ocular allergies, as well as acute and chronic forms of $\mathrm{AC}[17,18]$.

Corticosteroids can reach the eye via several administration routes. Intranasal corticosteroid sprays have demonstrated an additional advantage in reducing the symptoms of ocular allergies [19]. Currently, data related to the ocular effects of inhaled corticosteroids is limited [20]. ICS reduce airway inflammation and hyperresponsiveness, as well as their symptoms and severity, and prevent or reduce the occurrence of acute asthma exacerbations [2, 20]. Early childhood wheezing and asthma are heterogeneous disorders [1]. Respiratory viral infections, such as rhinovirus or respiratory syncytial virus, contribute to the development and exacerbation of asthma and have been positively correlated with the hospitalization of children with asthma [21]. A metaanalysis of preschoolers with recurrent wheezing and asthma demonstrated that daily ICS therapy could reduce exacerbations by nearly $40 \%$ [22]. Therefore, potential mechanisms that associate a reduced risk of glaucoma with the use of ICS may involve the inhibition 
Table 2: Correlation between comorbidities and the risk of developing glaucoma among asthma children

\begin{tabular}{|c|c|c|c|c|c|c|}
\hline & $\begin{array}{c}\text { No. of } \\
\text { patients }\end{array}$ & $\begin{array}{c}\text { No. of } \\
\text { person- } \\
\text { years }\end{array}$ & $\begin{array}{l}\text { No. of patients } \\
\text { with glaucoma }\end{array}$ & $\begin{array}{c}\text { Incident rate (per } \\
100,000 \text { person-years) }\end{array}$ & $\begin{array}{c}\text { Crude HR } \\
(95 \% \mathrm{CI})\end{array}$ & $\begin{array}{c}\text { Multivariate-adjusted } \\
\operatorname{HR}^{*}(95 \% \text { CI })\end{array}$ \\
\hline \multicolumn{7}{|l|}{ Age group } \\
\hline $0 \sim \leq 3.12 \mathrm{y}$ & 2684 & 32315.49 & 29 & 89.74 & 1.00 & 1.00 \\
\hline$>3.12 \mathrm{y}$ & 2696 & 32105.40 & 59 & 183.77 & $2.07(1.33 \sim 3.23)^{*}$ & $2.09(1.34 \sim 3.27)^{*}$ \\
\hline \multicolumn{7}{|l|}{ Gender } \\
\hline Female & 2071 & 24689.38 & 41 & 166.06 & 1.00 & 1.00 \\
\hline Male & 3309 & 39731.51 & 47 & 118.29 & $0.71(0.47 \sim 1.08)$ & $0.73(0.48 \sim 1.11)$ \\
\hline \multicolumn{7}{|l|}{ Income (NTD) } \\
\hline$<15840$ & 5298 & 63371.18 & 87 & 137.29 & 1.00 & 1.00 \\
\hline$\geq 15840 \sim<21900$ & 62 & 790.44 & 1 & 126.51 & $0.88(0.12 \sim 6.32)$ & $0.58(0.08 \sim 4.19)$ \\
\hline$\geq 21900$ & 20 & 259.27 & 0 & 0.00 & -- & -- \\
\hline \multicolumn{7}{|l|}{ ICS use } \\
\hline No ICS use & 4148 & 49696.16 & 76 & 152.93 & 1.00 & 1.00 \\
\hline Any ICS use & 1232 & 14724.73 & 12 & 81.50 & $0.54(0.29 \sim 0.98)^{*}$ & $0.52(0.28 \sim 0.96)^{*}$ \\
\hline \multicolumn{7}{|l|}{ Medical disease } \\
\hline \multicolumn{7}{|l|}{ Prematurity } \\
\hline Without Prematurity & 5351 & 64082.85 & 88 & 137.32 & 1.00 & 1.00 \\
\hline With Prematurity & 29 & 338.03 & 0 & 0.00 & -- & -- \\
\hline \multicolumn{7}{|l|}{ Myopia } \\
\hline Without Myopia & 2329 & 27819.58 & 33 & 118.62 & 1.00 & 1.00 \\
\hline With Myopia & 3051 & 36601.3 & 55 & 150.27 & $1.27(0.82 \sim 1.95)$ & $1.20(0.78 \sim 1.85)$ \\
\hline \multicolumn{7}{|l|}{ Cataract } \\
\hline Without Cataract & 5356 & 64146 & 85 & 132.51 & 1.00 & 1.00 \\
\hline With Cataract & 24 & 274.88 & 3 & 1091.39 & $\begin{array}{c}8.18 \\
(2.59 \sim 25.87)^{*}\end{array}$ & $8.22(2.59 \sim 26.12)^{*}$ \\
\hline \multicolumn{7}{|l|}{ Diabetes } \\
\hline Without Diabetes & 5333 & 63835.12 & 87 & 136.29 & 1.00 & 1.00 \\
\hline With Diabetes & 47 & 585.76 & 1 & 170.72 & $\begin{array}{c}1.23 \\
(0.17 \sim 8.82)\end{array}$ & $1.28(0.18 \sim 9.17)$ \\
\hline
\end{tabular}

a) CI, confidence interval; HR, hazard ratio; ICS, inhaled corticosteroids; NTD, New Taiwan Dollars.

b) ${ }^{*} \mathrm{p}<0.05$.

of chronic inflammation. ICS significantly decreases the need for oral corticosteroids in patients with severe asthma, thus indicating a decrease in systemic adverse events like glaucoma [19]. The various anti-inflammatory pharmacological mechanisms ascribed to ICS are the most likely causes for ICS's effectiveness on asthma. ICS has extensive anti-inflammatory properties to reduce airway, lung, and systemic inflammation. Most systematic absorption of ICS occurs through the lungs. Capable of reducing peripheral blood $\mathrm{T}$ cell activation and 'Th2type' cytokine mRNA expression, ICS therapy used to treat childhood asthma possesses immunosuppressive and anti-proliferative properties [23]. In one study involving childhood asthma, ICS treatment was found to decrease the blood eosinophil cationic protein concentration [24]. Another study of adults with chronic persistent asthma reported that ICS usage significantly reduced sputum and blood eosinophils [25]. Asthmatic patients in that study had various changes in biomarker levels after ICS therapy: $82 \%$ had a decreased fraction of exhaled nitric oxide values, $60 \%$ had decreased sputum eosinophil counts, and $58 \%$ had decreased urinary bromotyrosine 
levels (a biochemical fingerprint of eosinophil activation) [26]. Furthermore, nationwide population-based cohort studies have demonstrated that ICS can help protect against lung cancers and osteoporosis in patients with chronic obstructive pulmonary disease [20, 21]. The population-based prospective studies showed that among the prescription of antiasthma agents for children, ICS were used in 3.1-11.0\% of patients with asthma in Taiwan, with the rate varying by patient age and severity [27-29]. In this study, we also found that ICS was not frequently prescribed. The percentage of preschool-age children prescribed inhaled formulations was $22.9 \%$, while the other $77.1 \%$ were not prescribed ICS.

Worldwide, cataract is among the leading causes of visual disability in children [30]. The available literature has already found that children with congenital diseases (e.g., Marfan syndrome, Lowe syndrome) are at an increased risk for glaucoma and early cataract formation [31]. Therefore, physicians should pay attention to genetic background when dealing with these conditions. Furthermore, while secondary glaucoma is the most troubling complication of pediatric cataract surgery, previous studies have not yet been able to determine a definite association between glaucoma and cataract within the cohorts investigated. Interestingly, in this nationwide population-based study, we found that cataract patients were at an 8.22-fold increased risk of developing glaucoma. As a result, the intraocular pressure in this particularly high-risk group requires additional research.

Various studies have demonstrated a correlation between diabetes mellitus and glaucoma [32, 33]. Furthermore, many cases of myopia have been associated with an elevated likelihood of developing glaucoma [34]. However, no significant difference has been found between the myopia or diabetes groups and the control groups in preschool-age children with asthma. Statistical significance may be lacking due to a few different factors. First, the sample sizes of ICS users and glaucoma cases were small, thus resulting in a lack of statistical power. Second, school-age children and children without asthma were excluded from this study, creating a selection bias that may have affected the results. The diagnoses of glaucoma, asthma, and other comorbid diseases were mainly based on ICD-9-CM codes, another limitation. Furthermore, information on the severity of visual dysfunction and objective measures of visual impairment

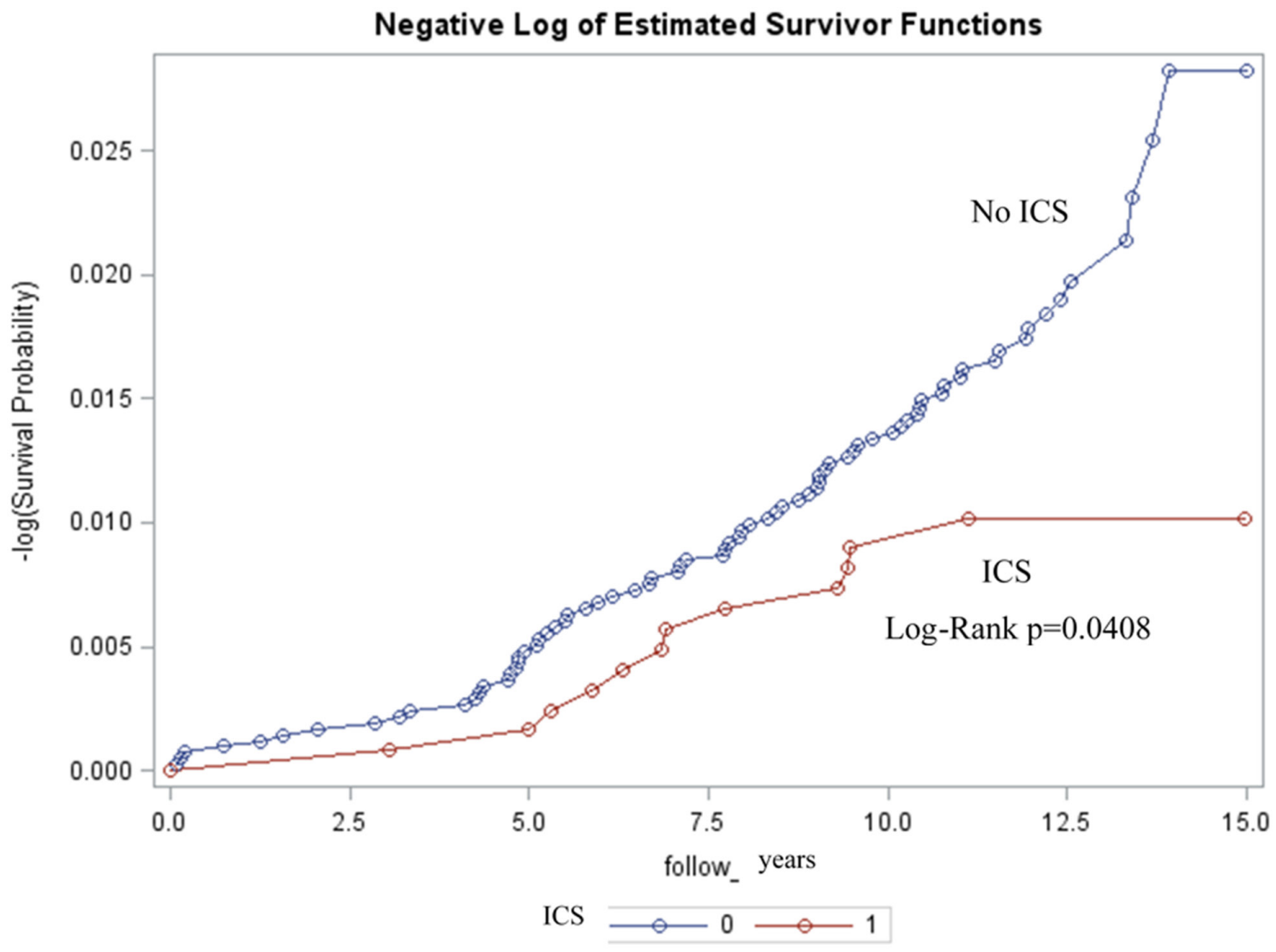

Figure 1: Kaplan-Meier estimates showing lower rates of glaucoma among patients with ICS (inhaled corticosteroid) $(p=0.0408)$. 
was lacking. We were also unable to overcome the immortal time bias in this study design, which is another potential weakness, as were the challenges in removing bias from immortal time. To prevent the methodological issue of the immortal time bias, which consists of the time between inclusion and the moment of first starting the ICS, more research is necessary in order to develop methods to remove immortal time bias [35]. The median cumulative dose of ICS was $23 \mathrm{mg}$, and no significant correlation was found between the cumulative dose ( $>23 \mathrm{mg}$ compared with $\leq 23 \mathrm{mg}$ ) of ICS and glaucoma. The incidence rate of glaucoma and cumulative dose of ICS are likely too low to examine the dose-effect relationships of glaucoma based on the ICS dose-stratified subgroups.

This study is likely the first to show that ICS use among preschool-age children with asthma is correlated with a significantly reduced glaucoma incidence. Clinicians should be particularly careful

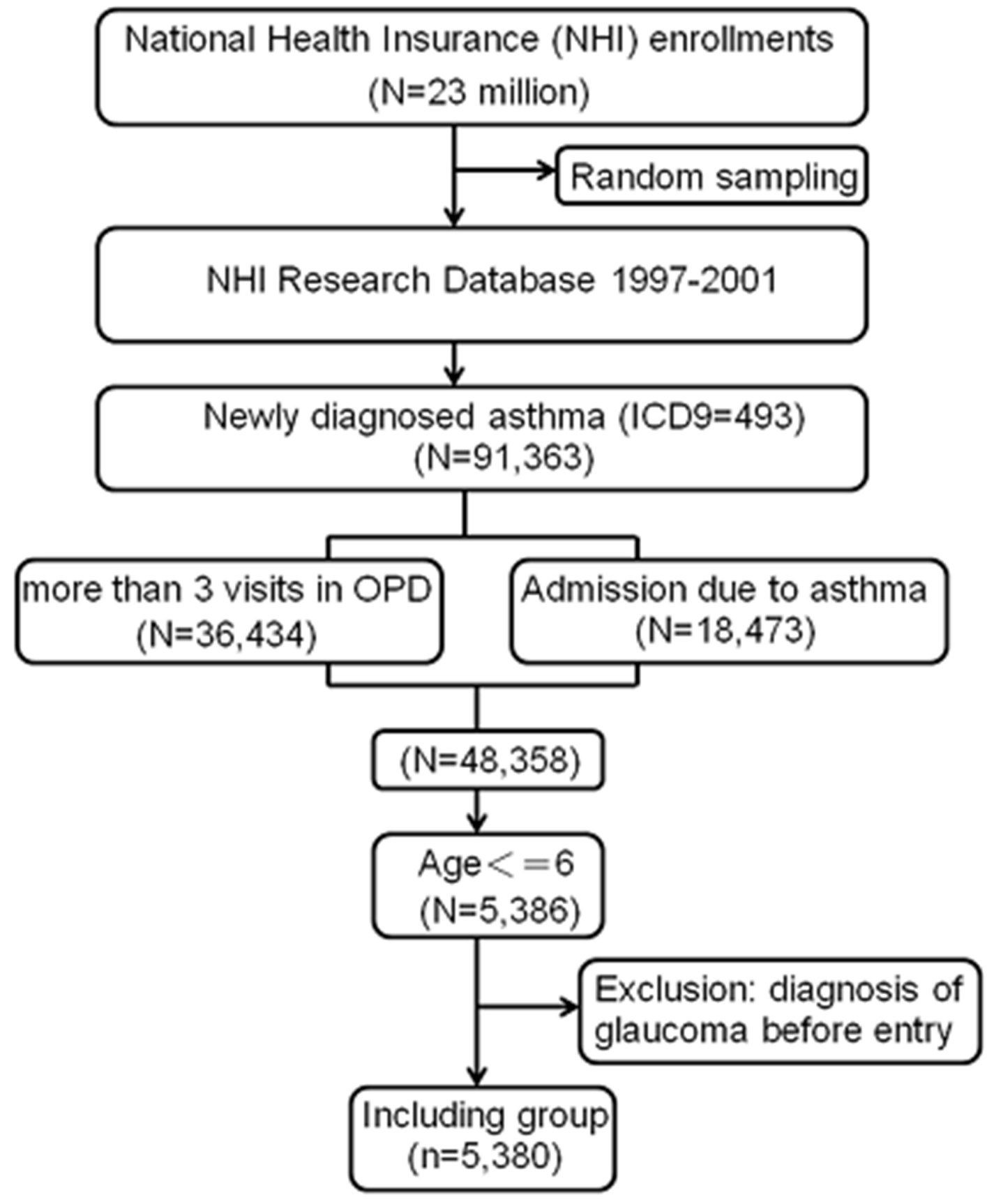

Figure 2: Flowchart of the enrollment process. OPD, outpatient department. 
when dealing with asthmatic children with cataract as they have a significantly increased risk of subsequently developing glaucoma. Additional consultation with an ophthalmologist is necessary for this high-risk group.

\section{MATERIALS AND METHODS}

\section{Ethics statement}

The Institutional Review Board of Kaohsiung Chang Gung Memorial Hospital in Taiwan approved this study (IRB No.102-0364B). The NHIRD provided the researchers with anonymous identification numbers prior to releasing the database, so the review board could exempt the requirement for written informed consent.

\section{Data sources}

Our data were obtained from a NHIRD subset known as the Longitudinal Health Insurance Database (LHID), which chose one million insured individuals at random from 1996 to 2000. This computerized database was derived from the Taiwan National Health Insurance Program, which was created in 1995. Said program offers universal health coverage and equal medical access to all Taiwanese citizens. Both hospitals and clinics in Taiwan are densely distributed and highly accessible and offer services at a very low cost, which motivates people in Taiwan to take advantage of such services. In 2011, the coverage rate of Taiwan's National Health Insurance was $99.6 \%$, so indicating that nearly the entire population of Taiwan (23 million) was enrolled in the program. The database consists of patient demographic information, gender, birth date, the registry for beneficiaries, diagnosis records (based on the International Classification of Diseases, 9th Revision, Clinical Modification [ICD-9$\mathrm{CM}]$ ), drug codes, diagnosis dates, admission dates, and procedures.

\section{Determining the asthma cohort}

Figure 2 shows the flowchart of the process we used to select the study population. A retrospective populationbased cohort study was conducted from January 1, 1997 through December 31, 2001. Based on the diagnostic codes for asthma in the NHIRD (ICD9: 493.X), we identified 5,380 children six years old or younger. We restricted the population to cases of newly diagnosed asthma in the LHID $(n=91,363)$ and further limited the analyses to patients with at least one hospital admission for asthma or at least three outpatient clinic visits for asthma, which we considered a validated diagnostic indicator of asthma $(n=48,358)$. After excluding subjects over the age of six years old, this study included 5,386 patients with new-onset asthma. We also excluded patients diagnosed with glaucoma before entry $(n=6)$, so our final asthma study cohort consisted of 5,380 children. According to their treatment therapies, we categorized patients with asthma who used ICS into the ICS group patients who had never used ICS into the unexposed group.

We chose certain demographic factors, like gender, age of asthma diagnosis, and comorbidities, to determine the potential risk factors related to glaucoma in children with asthma. We collected such data as prematurity (ICD9-CM 765), myopia (ICD-9-CM 367.1), cataract (ICD9-CM 366), and diabetes (ICD-9-CM 250) to adjust for the risk of glaucoma, focusing on the development of glaucoma as the relevant outcome. Patients diagnosed with glaucoma were identified from the database using the code 365.X in the ICD-9-CM format. The study's endpoint was the development of glaucoma. All children in our study cohort who did not develop glaucoma were followed through the end of 2011. Therefore, a sensitivity analysis was performed in which we excluded these patients who started ICS after a glaucoma diagnosis from our analysis.

\section{Statistical analysis}

To study the risk of asthma children developing glaucoma, descriptive statistical data of both ICS users and non-users are presented as a number and percentage for age group and comorbidities. We divided the case number from glaucoma by the number of person-years of followup to determine the incident rates. To define the correlation between ICS usage and potential risk factors, we estimated the hazard ratio (HR) and 95\% confidence interval (CI) using Cox proportional regression models. Furthermore, adjusted HR was corrected for potential bias sources. Results were considered statistically significant if $\alpha=0.05$. Data management and analysis were carried out using SAS 9.3 software (SAS Institute Inc, Cary, NC, USA).

\section{Abbreviations}

CI, confidence interval; HR, hazard ratio; ICS, inhaled corticosteroids; LHID, Longitudinal Health Insurance Database; NHI, National Health Insurance; NHIRD, National Health Insurance Research Database

\section{Author contributions}

Dr. Ling-Sai Chang and Ms. Hui-Ching Lee drafted the article, performed the initial analyses, and approved the final manuscript for submission. Ms. Shih-Feng Liu and Ms. Yuh-Chyn Tsai acquired the data, reviewed and revised the manuscript, and approved the final manuscript for submission. Ms. Lien-Shi Shen and Ms. Ching-Ling Li analyzed the data, reviewed and revised the manuscript, and approved the final manuscript for submission. Dr. HoChang Kuo conceived and carried out the design, acquired the data, revised the draft for intellectual content, and approved the version to be published. All authors have reviewed and agreed to this information prior to submission. 


\section{CONFLICTS OF INTEREST}

The authors have no conflicts of interest to disclose in relation to this article.

\section{FUNDING}

This study received support from a grant provided by the National Science Council, Taiwan (MOST: 105-2314-B-182-050-MY3 to HCK), as well as from grants provided by Chang Gung Memorial Hospital (CORPG8F0011， CMRPG8D0521， OMRPG8D0011, CMRPG8C1082, and CMRPG8E0211 to HCK) and by the Ministry of Science and Technology, Taiwan (MOST 106-2314-B-182A-110 to LSC).

\section{REFERENCES}

1. Bacharier LB, Guilbert TW. Diagnosis and management of early asthma in preschool-aged children. J Allergy Clin Immunol. 2012; 130: 287-96; quiz 297-298.

2. de Benedictis FM, Bush A. Corticosteroids in respiratory diseases in children. Am J Respir Crit Care Med. 2012; 185: 12-23.

3. Brand PL, Baraldi E, Bisgaard H, Boner AL, CastroRodriguez JA, Custovic A, de Blic J, de Jongste JC, Eber E, Everard ML, Frey U, Gappa M, Garcia-Marcos L, et al. Definition, assessment and treatment of wheezing disorders in preschool children: an evidence-based approach. Eur Respir J. 2008; 32: 1096-1110.

4. Philip J. The effects of inhaled corticosteroids on growth in children. Open Respir Med J. 2014; 8: 66-73.

5. Battaglia S, Cardillo I, Lavorini F, Spatafora M, Scichilone N. Safety considerations of inhaled corticosteroids in the elderly. Drugs Aging. 2014; 31: 787-796.

6. Razeghinejad MR, Katz LJ. Steroid-induced iatrogenic glaucoma. Ophthalmic Res. 2012; 47: 66-80.

7. Yamashita T, Kodama Y, Tanaka M, Yamakiri K, Kawano Y, Sakamoto T. Steroid-induced glaucoma in children with acute lymphoblastic leukemia: a possible complication. J Glaucoma. 2010; 19: 188-190.

8. Kwok AK, Lam DS, Ng JS, Fan DS, Chew SJ, Tso MO. Ocular-hypertensive response to topical steroids in children. Ophthalmology. 1997; 104: 2112-2116.

9. Chang WP, Wu SJ, Chang WC, Kuo HC. Population-based study of the association between urbanization and Kawasaki disease in Taiwan. ScientificWorldJournal. 2013.

10. Wong M, Huang P, Li W, Li Y, Zhang SS, Zhang C. T-helper1/T-helper2 cytokine imbalance in the iris of patients with glaucoma. PLoS One. 2015; 10: e0122184.

11. Tezel G. Immune regulation toward immunomodulation for neuroprotection in glaucoma. Curr Opin Pharmacol. 2013; 13: $23-31$
12. Huang P, Qi Y, Xu YS, Liu J, Liao D, Zhang SS, Zhang C. Serum cytokine alteration is associated with optic neuropathy in human primary open angle glaucoma. J Glaucoma. 2010; 19: 324-330.

13. Tseng VL, Lee GY, Shaikh Y, Yu F, Coleman AL. The association between glaucoma and immunoglobulin $\mathrm{E}$ antibody response to indoor allergens. Am J Ophthalmol. 2015; 159: 986-993.

14. Pecora L, Sibony P, Fourman S. Eye-rubbing optic neuropathy. Am J Ophthalmol. 2002; 134: 460-461.

15. Geraldini M, Chong Neto HJ, Riedi CA, Rosario NA. Epidemiology of ocular allergy and co-morbidities in adolescents. J Pediatr (Rio J). 2013; 89: 354-360.

16. Kim HY, Kwon EB, Baek JH, Shin YH, Yum HY, Jee HM, Yoon JW, Han MY. Prevalence and comorbidity of allergic diseases in preschool children. Korean J Pediatr. 2013; 56: $338-342$

17. Thong BY. Allergic conjunctivitis in Asia. Asia Pac Allergy. 2017; 7: 57-64.

18. Vichyanond P, Pacharn P, Pleyer U, Leonardi A. Vernal keratoconjunctivitis: a severe allergic eye disease with remodeling changes. Pediatr Allergy Immunol. 2014; 25: 314-322.

19. Hom MM, Bielory L. The anatomical and functional relationship between allergic conjunctivitis and allergic rhinitis. Allergy Rhinol. 2013.

20. Allen DB, Bielory L, Derendorf H, Dluhy R, Colice GL, Szefler SJ. Inhaled corticosteroids: past lessons and future issues. J Allergy Clin Immunol. 2003; 112: S1-40.

21. Meissner HC. Viral Bronchiolitis in Children. N Engl J Med. 2016; 374: 62-72.

22. Castro-Rodriguez JA, Rodrigo GJ. Efficacy of inhaled corticosteroids in infants and preschoolers with recurrent wheezing and asthma: a systematic review with metaanalysis. Pediatrics. 2009; 123: e519-525.

23. Gemou-Engesaeth V, Bush A, Kay AB, Hamid Q, Corrigan CJ. Inhaled glucocorticoid therapy of childhood asthma is associated with reduced peripheral blood $\mathrm{T}$ cell activation and 'Th2-type' cytokine mRNA expression. Pediatrics. 1997; 99: 695-703.

24. Prehn A, Seger RA, Torresani T, Molinari L, Sennhauser FH. Evaluation of a clinical algorithm involving serum eosinophil cationic protein for guiding the antiinflammatory treatment of bronchial asthma in childhood. Pediatr Allergy Immunol. 2000; 11: 87-94.

25. Aldridge RE, Hancox RJ, Cowant JO, Frampton CM, Town GI, Taylor DR. Eosinophils and eosinophilic cationic protein in induced sputum and blood: effects of budesonide and terbutaline treatment. Ann Allergy Asthma Immunol. 2002; 89: 492-497.

26. Cowan DC, Taylor DR, Peterson LE, Cowan JO, Palmay R, Williamson A, Hammel J, Erzurum SC, Hazen SL, Comhair SA. Biomarker-based asthma phenotypes of corticosteroid response. J Allergy Clin Immunol. 2015; 135: 877-883. 
27. Thomas M, Murray-Thomas T, Fan T, Williams T, Taylor S. Prescribing patterns of asthma controller therapy for children in UK primary care: a cross-sectional observational study. BMC Pulm Med. 2010; 10: 1471-2466.

28. Hamada S, Tokumasu H, Sato A, Iwasaku M, Kawakami K. Asthma controller medications for children in Japan: analysis of an administrative claims database. Glob Pediatr Health. 2015.

29. Sun HL, Lue KH, Kao YH. Prescribing patterns of antiasthma drugs in pediatric patients. Acta Paediatr Taiwan. 2005; 46: 212-218.

30. Medsinge A, Nischal KK. Pediatric cataract: challenges and future directions. Clin Ophthalmol. 2015; 9: 77-90.

31. Loi M. Lowe syndrome. Orphanet J Rare Dis. 2006; 1: 16.
32. Ong HS, Levin S, Vafidis G. Glaucoma detection using optic disc images from the English national screening programme for diabetic retinopathy. J Glaucoma. 2013; 22: 496-500.

33. Bonovas S, Peponis V, Filioussi K. Diabetes mellitus as a risk factor for primary open-angle glaucoma: a metaanalysis. Diabet Med. 2004; 21: 609-614.

34. Smith MJ, Walline JJ. Controlling myopia progression in children and adolescents. Adolesc Health Med Ther. 2015; 6: 133-140.

35. Yang XL, Huo XX, Chan JC. Methodological challenges to control for immortal time bias in addressing drug effects in type 2 diabetes. World J Methodol. 2015; 5: 122-126. 